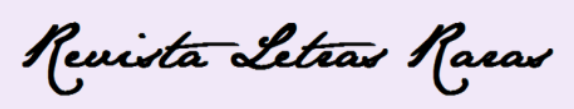

ISSN: 2317-2347 Vol. 5, Ano 5, № 1 - 2016

\title{
Os diafragmas do mundo interstício e interfaces na obra de Antônio \\ Tabucchi
}

Perle Abbrugiati*

A obra de Antônio Tabucchi é uma obra caracterizada por ser "de lacunas" - se uma coisa foi dita pela crítica sobre este autor contemporâneo, é esta: pela supressão de um "C", o jogo de palavras "buchi/Tabucchi"" resume em todas as jornadas de estudo que são consagradas a este autor, e se associa, em geral, esse capricho, à uma estética da elipse: na tessitura narrativa tabucchiana sentimos as faltas nas quais a estratégia narrativa repousa paradoxalmente. Que a elipse seja fundamental em um suspense baseado na evasão de pressupostos dos acontecimentos, ou a expressão estilística de uma ocultação da consciência seja ligada aos remorsos, a falta de narração de certos fatos é um componente essencial da narrativa tabucchiana, que é correlata ao assombramento do tema da falta no mundo afetivo das personagens. Essa complacência pela elipse, que nos casos limites são o não narrado do encontro com Isabel em Réquiem, por exemplo, e a discussão minuciosa do advogado Lotòn em A cabeça perdida de Damasceno Monteiro; é abundantemente comentada pela crítica tabucchiana. Citaremos apenas dois exemplos. Vejamos o que diz Pia Scharz-Lausten:

Existem pelo menos duas formas de elipse na narrativa de Tabucchi: uma onde se acena a algo no conto, que permanece silenciada, e outra onde não vem nenhum dito, nenhuma sugestão, mas onde se sente um espaço vazio na tessitura textual. ${ }^{3}$

Vejamos também o que diz Alessandro Iovinelli que aproxima Tabucchi das concepções cosmológicas contemporâneas:

Com Tabucchi somos tentados a arriscar dizer que - ao fundo de seu complexo sistema de escrita - o não dito, o inexpresso, o não acontecido, a

\footnotetext{
1 Versão em Português de Les diaphragmes du monde. Interstices et interfaces dans l'oeuvre d'Antonio Tabucchi. 2008, feito por Glauber Rezende Jacob Willrich, mestrando em teoria literária pela Universidade Federal do Paraná (UFPR), e licenciado em Letras Francês pela Universidade Federal de Uberlândia (UFU). Email: glauber_rad@hotmail.com.

* Doutora em estudos italianos, e professora do departamento de italiano da Universidade de Provença.

${ }^{2} \mathrm{~N}$ do $\mathrm{T}$ : Em italiano, buchi significa vazio, buraco, orifício. O jogo de palavras, então, se refere à narrativa de Tabucchi por ser caracterizada com furos e vazios.

${ }_{3}^{3}$ Pia Schwarz-Lausten, L'uomo inquieto. Identità e alterità nell'opera di Antonio Tabucchi, Copenhague, Museum Tusculanum Press, 2005, p. 98.
} 


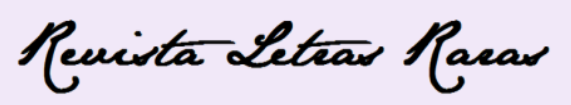

ISSN: 2317-2347 Vol. 5, Ano 5, № 1 - 2016

falta, em suma, o que não é, tem uma função decisiva, de certo a mais decisiva. Um pouco como na teoria de "Buchineri" elaborada por Roger Penrose e mais tarde por Stephen Hawking, o universo é constituído de matéria e antimatéria, e esta última, cuja presença pode ser provada apenas indiretamente - como dizia o físico John Archibald Wheeler: "um buraco negro não tem cabelo" -, constitui a origem de todos ou quase todos os problemas que a cosmologia deve enfrentar e superar. ${ }^{4}$

Mas essa importância faz juz ao ressaltar as "lacunas" elípticas, porque ela se situa no interior da narração, e não parece dar conta completamente da natureza própria da narração tabucchiana. Não é somente na narrativa que há lacunas, é a narrativa ela mesma que parece corroída por não ser, que parece pertencer a uma dimensão precária se nos remetemos, por exemplo, à nota introdutiva de Volatili Del Beato Angelico (As aves do beato Angélico), onde lemos sobre a caneta de Tabucchi:

Hipocondria, insônia, intolerância e mágoas são as musas coxas dessa breve página. Gostaria de intitular Extravagância, não tanto por seus caracteres, mas sim porque muitos deles me lembram vagamente como algo que não possui um interior, como lascas à deriva sobreviventes a um tudo que nunca foi. Estranhos para cada órbita, tenho a impressão que navegam em espaços confidenciais de formas desconhecidas; digamos fractais domésticos: a zona intersticial do nosso cotidiano deve ser determinada ou talvez enverrugada pela nossa existência. ${ }^{5}$

Não é somente o todo que não é contado, mas a narrativa ela mesma é próxima da inexistência. Não há nenhuma dúvida que a definição que Tabucchi dá, mais tarde no mesmo texto, de "prosa lacunosa", de "quase narrativa", que engendra a perplexidade própria aos seres embrionários ("tem natureza larval, se exibem como que criaturas soltas ou em formol, com aqueles olhos grandes de corpos fetais - olhos que interrogam.”) poderia corresponder com outros textos tabucchianos além dos de Volatili. Ela cai como uma luva, por exemplo, à maioria dos textos de Donna di Porto Pim (A mulher de Porto Pim), e não é estranha à estética de Si sta facendo sempre più tarde (Se está fazendo sempre tão tarde). De fato, em toda narrativa de Tabucchi, com dosagens diferentes, encontramos a essência de certa literatura do quase lacunoso: é o que relembraremos destra introdução - uma escrita "fractal" para explorar as "zonas intersticiais".

\footnotetext{
${ }^{4}$ Alessandro Iovinelli, I dialoghi manca(n)ti di Antonio Tabuchi, in Echi di Tabucchi /Echos de Tabucchi, actes du colloque international d'Aix-en-Provence, $12-13$ janvier 2007, "Italies", 2007, p.150-151

${ }^{5}$ Antonio Tabucchi, Nota introdutória de I volatili Del Beato Angelico, Palerme, Sellerio, 1987, p. 9
} 


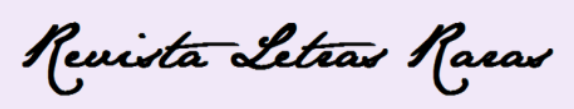

ISSN: 2317-2347 Vol. 5, Ano 5, № 1 - 2016

Da mesma forma, mais que uma escrita "de lacunas" (no qual concordamos de fato), a narrativa tabucchiana nos aparece como uma literatura de interstício. O interstício figura, por outro lado, frequentemente como tema que se entrelaça à narrativa. Pensemos, por exemplos, nas passagens-chave que se abrem sobre essa noção: A Carta de Calipso, Ninfa, a Odisseu, rei de Itaca, ela olha, na ninfa leopardina, os espaços entre as estrelas: "a noite eu olho para o espaço entre as estrelas, vejo o vazio sem medida." ${ }^{6}$. Ou mesmo o narrador de Messagio dalla penombra (Mensagem da penumbra), que vive "no tempo deste infinito mínimo, que é o intervalo entre meu tempo e nosso tempo."7 Interstício no espaço, intervalo no tempo, a literatura de Tabucchi é uma literatura de entre-lugares, talvez seja essa a razão que se dá à narrativa de Rebus, em Picoli equivoci senza importanza (Pequenos equívocos sem importância): “Talvez porque a razão seja covarde, ela não pode preencher a lacuna entre as coisas para estabelecer a competência do que é uma forma de simplicidade. Ela prefere uma complicação cheia de lacunas." As "lacunas" tabucchianas, tanto e mais que as elipses narrativas, são "lacunas entre as coisas". Essas lacunas são entre... entre as coisas. É por isso que nos interessamos aqui, sobretudo, nessas cavernas escuras do "entre".

\section{Uma obra de entre-lugar}

Tonino, o narrador de Pequenos equívocos sem importância, está "entre uma bola e outra"9. O navio que Don Sebastião de Aviz pede a Goya é representado em Passato composto (passado composto). Tre lettere (três cartas) está "entre as nuvens e o céu" 10 . O texto encontrado em Forbidden Games é "uma carta sem garrafa que navegou quem sabe em algum diafragma do mundo". ${ }^{11}$

Os "diafragmas do mundo" se mostram bem como o espaço privilegiado da consciência tabucchiana, estreitas aberturas fugitivas e pouco perceptíveis entre duas realidades, fendas que separam mais ou menos o indivíduo entre duas dimensões.

\footnotetext{
${ }^{6}$ Lettera di Calipso, p. 33

${ }^{7}$ Messagio dalla penombra, p. 41

${ }^{8}$ Rebus, in Picoli equivoci senza importanza, Milan, Feltrinelli, 1985, p. 29.

${ }^{9}$ Picoli equivoci senza importanza, ibidem, p. 10

${ }^{10}$ Carta de Don Sebastião de Aviz, in I volatili Del Beato Angelico, cit., p. 25.

${ }^{11}$ Forbidden Games, in Si sta facendo sempre più tardi, Milan, Feltrinell, p. 45.
} 


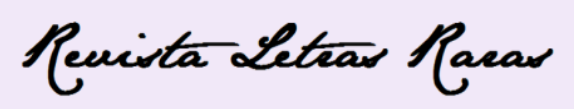

ISSN: 2317-2347 Vol. 5, Ano 5, № 1 - 2016

- A primeira dessas linhas de falha, o primeiro diafragma é este que coloca os personagens tabucchianos entre presente e passado.

A narração retrospectiva que reflete uma memória obsessiva se nutre de vai-e-vem incessante entre as dimensões temporais incompatíveis, que os narradores sobrepõem ou confundem, ou entre as quais eles fazem uma viagem sem fim. A saudade, que parece ser o pivô de toda escrita subjetiva em Tabucchi, se traduz, com efeito, por resultados narrativos recorrentes dos mais variados. Assim, alguns dos protagonistas escapam de seu presente em uma deriva que os leva ao passado, e eles retornam para um ponto do tempo que os focaliza e os abstrai da atualidade: o personagem de Rebus não supera sua aventura com Myriam; aquele de Il fuime (O rio) é fechado em um bloqueio de memória. Outros comparam o momento presente à suas vidas passadas: o terrorista de Troca de Mão constata que sua lembrança à Causa não é mais a que ele era, o aposentado da polícia política de Os Mortos na mesa questiona como o mundo mudou desde a queda do muro de Berlin; o professor de $I l$ rancore e le nuvole (O rancor e as nuvens) compara sua antiga pobreza a seu prestígio atual; em Forbidden Games o abismo parece incomensurável entre o antigo boêmio parisiense e o presente.

Outros misturam os tempos e os integram, se deixando ao sonho ou a doce loucura: Pequenos equívocos sem importância é uma superposição de duas situações distantes em pelo menos vinte anos, Gli archivi di Macau (Os arquivos de Macau) evocam em transparência um passeio de lambreta durante uma aterrissagem de avião; Carta para escrever atribui idades diferentes aos mesmos personagens sob efeito de uma vertigem senil ou de uma infinita nostalgia; Sono venuto a trovarti ma non c'eri (Eu vim para te ver, mas você não estava) põe em cena um homem que perdeu toda noção do tempo, na recusa de um evento que o arruinou. Outros, enfim, se encontram presos em uma impossível inscrição no tempo que pode levá-los ao suicídio, ou, em todo caso, os fazem renunciar à vida: o músico de $A$ che cosa serve un'arpa con una corda sola (Para que serve uma harpa com uma corda só) se exila de seu pais e da vida ela mesma, depois do trauma do holocausto; o protagonista de La circolazione del sangue (A circulação do sangue) se suicida sob a influência de uma decepção amorosa quando eles não exploram deliberadamente o passado para expurgar sua consciência de seu luto necessário: é este todo o sentido de Réquiem. 


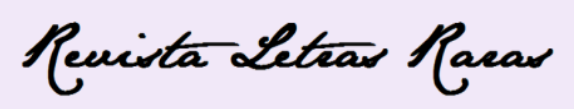

ISSN: 2317-2347 Vol. 5, Ano 5, № 1 - 2016

Qualquer que seja sua atitude em relação ao passado - constatação irremediável do abismo ou mosaico de lembranças que imbricam os tempos - os personagens não vivem nem em um tempo nem em outro. Elas ficam como que em suspensão em um intervalo que as faz oscilar no movimento perpétuo de uma analepse balbuciante, à margem da vida, expectadores de sua atualidade como de seu passado mistificado, conscientes de uma falha conservada por uma nostalgia compulsiva.

Ao mesmo tempo, é pela escolha dessa fissura como lugar de seu pensar, que se abre um espaço criativo. O vai-e-vem entre os tempos é a melhor maneira de fugir do tempo presente (mesmo que os saibamos axiomaticamente como vítimas), pois essa dimensão do entre-lugar, que não existe em verdade, é um espaço de invenção: a memória, essa memória falsária como escreve Tabucchi, ressuscita e transforma, embeleza e modifica, trai, mas crê, intervém demiurga. Os personagens se privam, portanto, do presente, mas se inventam em um tempo somente delas, que as marginaliza e as transcende juntas. É apenas ao preço da interferência de temporalidades que nasce uma consciência "além-do-tempo", pelo qual os protagonistas-narradores se fazem artistas de sua vida, como a tesoura da memória que esculpe e remodela à vontade o vivido e o não vivido. Modelando o tempo sem parar, os personagens produzem um monumento de eternidade, quando, apesar de tudo, eles deveriam sofrer, já que a eternidade, como diz Calipso, é um exílio. Dennis Ferraris nos ajuda a esclarecer essa noção de modelamento em relação à narrativa:

Para Tabucchi, a literatura vive de sonhos, de imaginação e de lembranças. E, entretanto, sua verdade revela uma autenticidade no qual suas marcas não são inscritas no real anterior no qual ela se alimenta: é ela mesma que foge a seus princípios, que dão forma e que as modelam/amassam, se queremos encontrar a etimologia dos fenômenos da ficção. ${ }^{12}$

Os personagens se isolam, portanto, no arquipélago do tempo que eles remontam, não explorando de fato suas ilhas, mas passando com mais clarividência de suas vidas a navegar nas correntes que os separam. É dessa ondulação que é feito o ritmo da prosa tabucchiana, que segue a oscilação das consciências moídas, mas rendidas à criatividade por sua dor lancinante.

\footnotetext{
${ }^{12}$ Denis Ferraris, Les vérités de la mémoire et de l'écriture dans l'oeuvre de Tabucchi, in Echos di Tabucchi/Echos de Tabucchi, cit. P. 104-105.
} 


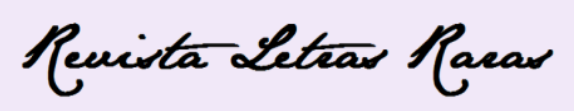

ISSN: 2317-2347 Vol. 5, Ano 5, № 1 - 2016

Inversamente, a criação propriamente dita, compreendida na escrita, só pode ser um entre-lugar, algo entre formulação e silêncio, para permanecer a imagem de um fluxo e não de algo fixo: é a este preço que ela não mais se fossiliza em um tempo dado, mas acaba como que suspensa entre um estado de consciência e outra, "exterior à toda órbita", emergência perpétua e resultado evitado.

- O segundo "diafragma do mundo" onde residem os textos tabucchianos é aquele que se situa entre o sonho e a realidade.

Os personagens de Tabucchi não sabem permanecer sobre um só plano de realidade. Quando eles não passeiam de um plano temporal a outro, eles mudam de plano de consciência. O sonho é, de fato, o lugar ideal para modular o real. Ele vem como apoio da "retrospecção inventiva" que opera na memória, tendo não somente o lugar de representações fantasmagóricas, mas também o terreno onde a mistura de tempos é possível: no sonho, podemos não somente rever figuras do passado (Tadeus), mas atribuir-lhe a idade que nos convém (o pai em Réquiem), ser simultaneamente alguém mais novo e mais velho (Os arquivos de Macau), fazer coexistir elementos que pertencem a épocas separadas (O jogo do reverso), convocar figuras históricas (Noturno Indiano), dar vida de forma fantástica a uma mitografia familiar (Capodanno), etc.

E o que é real no sonho é verdadeiro, com graus diversos que vão desde as formas do sonhar acordado passando pelo devaneio e pela alucinação. Distinguiremos, portanto, os sonhos "verdadeiros" - oriundos dos personagens que dormem - das situações alucinatórias; e, sobre o plano da escrita, o sonho como forma (Sogni di sogni/sonho do sonho) do onirismo que contamina a narrativa (Se está fazendo sempre tão tarde).

Os personagens de Tabucchi, sempre lembrando, apresentam um paradoxo: eles vivem em uma consciência vaporosa, feita de imprecisão e de relação com o tempo flutuante; ao mesmo tempo em que eles não têm uma relação instantânea com a materialidade: eles comem (frequentemente) e dormem. Mas se os momentos de refeição são intermédios concretos no discurso sobre o inefável (diálogos ou discursos interiores), o sonho não exprime somente a corporeidade dos personagens: é, ao contrário, sempre o pretexto para entrar no domínio do sonho, onde poderão ter vivido situações, ter tido pensamentos de obsessão, e formulado mensagens. O sonho é, então, a ocasião de fugir, ou, ao contrário, de se expressar, 


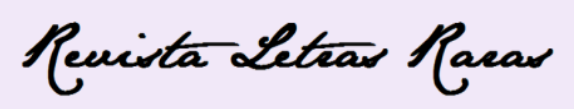

ISSN: 2317-2347 Vol. 5, Ano 5, № 1 - 2016

ou ainda de se apropriar das verdades confusas. Os personagens que dormem e sonham são muitos: citemos, para lembrar, o fim do Jogo do Reverso onde o protagonista se junta no sonho com Maria do Carmo na mesa das meninas; o fim de Capodanno onde o personagem passeia em um espaço submarino; o fim de Rebus, onde o personagem sonha com Myriam em uma praia deserta; a espera de Roux na Sociedade de Teosofia, em Noturno indiano, durante o qual ele se encosta para cochilar, e sonha com o vice-rei das Índias; o sonho de Réquiem, onde o narrador fala com seu pai quando era jovem, etc. Os sonhos são tão numerosos que seria difícil elencá-los todos, portanto, nos restaremos aqui especialmente porque não é mais a situação do sonho oriundo do ato de dormir que nos interessa.

De fato, as situações de entre-lugares da consciência são mais pertinentes ao objeto que tratamos aqui: o estado dos personagens que não dormem, e que, portanto, não sonham, mas estão constantemente próximos de uma situação onírica, é mais representativo da noção de interstício que nos interessa. Entre consciência desperta e representação mental, os personagens mais interessantes são aqueles que caminham interiormente nas passagens quiméricas alojadas entre sonho e miragem. Assim, todo Réquiem, uma alucinação, como indica o subtítulo, faz o narrador viajar em um espaço de devaneio onde tudo é possível e sem o qual nenhum luto não seria feito. O narrador de Pequenos Equívocos sem importância, sem jamais ceder ao sonho, vive o processo no qual ele assiste como um sonho, contaminando-o com um outro grau de realidade, aquele da memória atualizada e tranquilizada. O poeta de $L a$ trota che guizza mi ricorda la tua vita (a truta que se contorce me lembra tua vida) se abstrai de um pseudo-diálogo com sua mulher morta, da mesma maneira que Pereira com sua mulher em Afirma Pereira. A protagonista de Voici vive em uma projeção fantasmagórica da presença de seu bem-amado que a deixou; os personagens de Forbidden Games ou de Any Where out of the world, com tonalidades diferentes, revivem o passado com uma força tal que seus sonhos prejudicam sua visão.

Os personagens de Se está fazendo sempre tão tarde contam os fatos que parecem sempre fora de seu imaginário mais real. O protagonista de Um bilhete no meio do mar está, de fato, em uma ilha ou imagina ele uma viagem que teria desejado fazer com uma mulher que não se manifesta lá, bem como poderia não ser lá a cena que ele descreve? Aquele personagem do sonho de Sono passato a trovarti ma non c'eri (eu vim para te ver, mas você não estava), saiu, de fato, da clínica da Villa Serena ou fez ele uma exploração mental para 


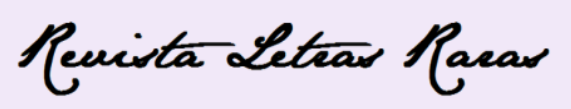

ISSN: 2317-2347 Vol. 5, Ano 5, № 1 - 2016

encontrar seu antigo domicílio? Já aquele sonho de Lettere da Scrivere (carta para escrever) não superpõe a infância de seu filho e de sua filha com sua situação quando adulto em uma lógica similar a do sonho, enquanto ele não dorme? O moscone de Tristano é real ou objetiva ele seu "rumore di fondo fatto scrittura? ${ }^{13 "}$ (Ruído de fundo que faz a escrita?). E o autor no qual Tristano se dirige, tão silenciosamente, é bem presente por entender sua soliquitude, ou não, como certos interlocutores de Se está fazendo sempre tão tarde, uma projeção de sua imaginação delirante? E assim por diante: aqui também seria difícil listar exaustivamente os personagens que inventam sua vida presente, como outros personagens tabucchianos que reinventam sua vida passada.

Podemos dizer que se, de um lado, a narração do sonho faz sempre uma incursão na prosa tabucchiana, se Tabucchi se eleva mesmo a um gênero a parte em Sogni di sogni (sonho do sonho), a presença do onirismo é ainda mais interessante quando ela é difusa e invade a narrativa com uma realidade, colocando o leitor em contato com uma subjetividade elegida como lugar de pensamento de um entre-lugar, entre percepção e interioridade.

- O terceiro "diafragma do mundo" que podemos identificar na obra de Tabucchi é o interstício entre consciência e inconsciência, se pensarmos que a maioria dos textos repousam sobre a ideia de um trauma ou remorso

A busca de um sentido para acreditar entre membros de frases recolhidas ao acaso em Voici portate da qualcosa, impossible dire cosa (aqui há algo, impossível dizer algo) por uma improvável colagem que faria circular o sentido nas junções de fragmentos sem revelação prévia, liga uma poética de intermitência ao tema do remorso - tão forte aqui que leva o protagonista ao suicídio.

Formularemos a hipótese de que as declarações vinculadas à confissão misturadas com o imaginário são uma maneira de suportar uma relação com o real de ordem traumática juntamente com a evolução involuntária na imaginação da parte dos protagonistas que não são criadores. O texto exemplar neste sentido é Libri mai scritti, viaggi mai fatti (Livros nunca escritos, viagens nunca feitas), que põe em cena uma poética de criação de um vazio, e mesmo da existência do vazio: não mais viver, não mais escrever, que se transforma nesse texto em sinônimos de viver e escrever intensamente, segundo um processo de inversão

\footnotetext{
${ }^{13}$ Nota introdutória de I Volatili Del Beato Angelico, cit.
} 


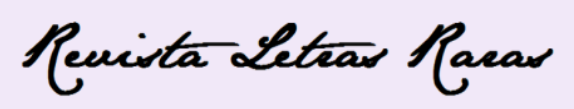

ISSN: 2317-2347 Vol. 5, Ano 5, № 1 - 2016

sistemática de termos, é a única maneira de lidar com a traição (da personagem feminina) e com a morte (o texto termina com as palavras ich sterbe - eu morro). Este texto, que é uma maravilhosa apologia do imaginário, é também o traço de uma contusão que faz do imaginário a linha de frente entre o consciente e o inconsciente - frente que é realmente uma luta, tanto quanto uma complementaridade. Um polemos (uma guerra), para concordar com os pré-socráticos, que revela um symbolon (união indissociável dos contrários).

Se os personagens são apaixonados por essa linha Maginot ${ }^{14}$ de pensamento é também porque é somente lá - entre Logos e irracional - que eles percebem as irisações do ser, quando não é nunca feita de contrastes distintos: as conclusões existenciais dos protagonistas são sempre da ordem da complexidade da existência, da complexidade da intimidade do ser e da complexidade do real. "Una cosa che era "cosi" era invence anche in un altro modo" (Uma coisa que era "assim”, foi, em vez disso, de outro modo), diz o prefácio da segunda edição do Jogo do reverso ${ }^{15}$.

O equívoco é a palavra de ordem de um mundo ambíguo tendo os "nadas" ("che cosa guida le cose? Un niente.../O que guia uma coisa? Um nada...) É, portanto, na intraçável fronteira entre consciente e inconsciente que se encontram as verdades reversíveis dos personagens. De lições de vida tanto quanto problemas inúteis, que parecem confirmar a palavra leopardiana segundo a qual "l'ultima conclusione che si ricava dalla filosofia vera e perfetta, si è, che non bisogna filosofare. ${ }^{16 "}$ (a última conclusão que ocupava a filosofia verdadeira e perfeita, se existe, é a de que não precisa filosofar.)

Portanto, essa forma incerta de consciência (coscienza) é de fato uma forma de consciência (consapevolezza) ${ }^{17}$ que, se escapa às incertezas, não se justifica ao menos - e justamente por ela - pela escrita: é o que diz no fim da nota introdutória das Aves do Beato Angélico:

\footnotetext{
${ }^{14} \mathrm{~N}$ do T: linha de fortificações e de defesa construída pela França ao longo de suas fronteiras com a Alemanha e a Itália, após a Primeira Guerra Mundial, mais precisamente entre 1930 e 1936.

${ }^{15}$ Il gioco Del rovescio, Milan, Feltrinelli, 1999 (primeira edição de Feltrinelli 1988, precedida da edição Milan, Il Saggiatore, 1991), p. 5

${ }^{16}$ Giacomo Leopardi, Dialogo di Timandro e di Eleandro, in Operette morali, Naples, Guida, 1986, p. 358

${ }^{17} \mathrm{~N}$ do T: Em italiano ambos os termos significam "consciência", mas designam sentidos diferentes. O primeiro se refere a uma consciência da realidade objetiva, exterior, a partir das atividades cognitivas. O segundo já se refere à consciência voltada para a apreensão do interior, subjetiva e individual.
} 


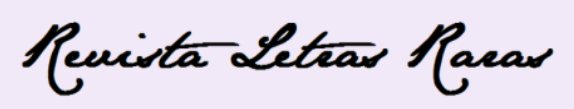

ISSN: 2317-2347 Vol. 5, Ano 5, № 1 - 2016

Se da preguiça [...] não conceder opção e plenitude, resta sempre a elas a possibilidade de alguma palavra desfigurada: e tanto vale dizer. Uma forma de consciência que não se confunde com o nobre estoicismo, nem mesmo com a resignação. ${ }^{18}$

- Expressão de um pensamento falho, talvez, no sentido onde entende Vattimo ${ }^{19}$, as constatações às quais alcançam os personagens-narradores de Tabhucchi não as comportam menos uma essencialidade, provavelmente porque o "quarto diafragma do mundo" (o último do qual consideraremos neste estudo) é aquele referente ao hiato entre a vida e a morte.

São numerosos os personagens tabucchianos que erram entre um aqui e acolá. "La poesia è un buon viatico" (a poesia é um bom viático) diz Tadeus em Notte, Mare e distanza ${ }^{20}$ (noite, mar e distância). E ele sem dúvida sabe que a escrita tabucchiana corresponde sempre a essa definição. Réquiem, no seu conjunto, é um diálogo com os mortos - pai, amigo, amante, autor admirado. Pereira não fala senão com sua mulher morta. Don Pedro se casa com um cadáver. Buone notizie da casa (boa notícia de casa) é ainda a verborragia de um viúvo, como sem dúvida Lettera da Scrivere (carta para escrever). À lista de viúvos devemos acrescentar, entre outros, o pescador de arpão de Donna di Porto Pim, o Berlinois de I morti a tavola (os mortos na mesa), Tristano, e alguns outros viúvos também (Esterina, Esperia, a mãe de Incanti, a esposa de Aspettano L'inverno/esperando o inverno, a destinatária de Messagio dalla penombra/mensagem da penumbra, Calypso à sua maneira, etc.). Como se a solidão fosse também a ocasião de uma palavra sobre o vazio.

Antes de passar para a melancolia omnipresente, Tabucchi escrevia Piazza d'Italia (Praça da Itália), como uma homenagem a seus ancestrais mortos que gravitam em torno de um monumento aos mortos. Todos os personagens de Se está fazendo sempre tão tarde estão imersos em uma fala dirigida a um "defunto", que são seus entes queridos mortos, ou desejam que os estejam.

Os personagens de Roux, em Noturno indiano, e de Spino, em Il filo dell'orizzonte (o fio do horizonte), estão à procura de um morto - que para alguns dos protagonistas, não é outro senão eles mesmos [o interlocutor indiano de Tabucchi em "la frase che segue è falsa.

\footnotetext{
${ }^{18}$ Antonio Tabucchi, I volatili Del Beato Angelico, cit., p. 10.

${ }^{19} \mathrm{~N}$ do T.: Se refere aqui ao pensamento do filósofo italiano Gianni Vattimo.

${ }^{20}$ Notte, maré e distanza, in L'angelo Nero, Milan, Feltrinelli, 1999 (1991), p. 32.
} 


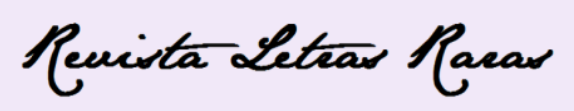

ISSN: 2317-2347 Vol. 5, Ano 5, № 1 - 2016

La frase che precede è vera" (a frase que segue é falsa, a precedente é verdadeira) define Noturno indiano assim: "esse é todo um livro sobre a morte"21]. Assim, a relação com o tempo ele mesmo é um pensamento de morte: a morte continuada daquilo que somos ou éramos, o tornar-se sendo apenas uma morte em movimento, a vida ela mesma se confundindo com um incessante morrer. "Perche per tornare ad essere ciò che fu, dovrebbe essere ció che fu, e questo è impossibile ${ }^{22 " ~(P o r q u e ~ p a r a ~ s e ~ t o r n a r ~ a o ~ q u e ~ e r a ~ a n t e s, ~ e ́ ~ p r e c i s o ~}$ voltar a ser o que era, e isso é impossível). Não é por acaso que é Atropos, o terceiro parque, a morte, que fecha Se está fazendo sempre tão tarde, tanto quanto é responsável pelas ligaçõeschaves para a empreitada da existência. Quanto a Tristano, ele está situado propriamente entre a vida e a morte, e é desta situação de agonia que jorra sua palavra caótica.

Os personagens de Tabucchu, habitados por seus fantasmas que são elevados às categorias de personagens (Tadeus, Isabel, as mulheres já mencionadas a que falam todos os viúvos e as negligenciam), circulam em uma fenda entre vida e para além dela, e se instalam como para melhor continuar a dialogar com aqueles que não estão mais presentes. Um diálogo no qual a interrupção confirmaria que qualquer coisa deles mesmos está morta: é através somente destes que eles nos dizem o que somos, e seu desaparecimento nos extinguem em parte com eles. Assim também, o pensamento dos personagens toma, portanto, sempre um perfil dialógico (apesar de, às vezes, assumirem a forma monológica: eles falam com os mortos ou mesmo com eles mesmo). A sistematização da procedência de Réquiem (diálogo com os antepassados) ou em Se está fazendo sempre tão tarde (no qual podemos qualificar as cartas de mensagem da penumbra), ou ainda em Tristano Morre, devem nos fazer lembrar que existe, também, de maneira mais difusa na consciência de outros personagens, um sutil dialogismo que trai a relação a um "para além" sem interrupção, ou a um sentimento de morte consubstancial à vida. Pia Scharz-Lausten formula da seguinte maneira:

A memória coloca em cena um diálogo entre vários interlocutores, diversos também no tempo. Mas essa é ainda uma estratégia para colocar em cena um diálogo com outro fora de si, outra pessoa, que apesar de sempre elusiva, inexiste no universo da narrativa de Tabucchi. ${ }^{23}$

\footnotetext{
${ }^{21}$ I volatili Del Beato Angelico, cit., p. 44.

${ }^{22}$ Si sta facendo sempre più tardi, cit., p. 209.

${ }^{23}$ Pia Schwarz-Lausten, op. Cit., p. 60.
} 


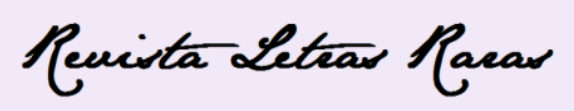

ISSN: 2317-2347 Vol. 5, Ano 5, № 1 - 2016

Assim, portanto, Tabucchi joga com personagens que, entre presente e passado, entre sonho e realidade, entre consciente e inconsciente, entre vida e além pertencem a dois mundos de cada vez, não sabendo escolher uma definição única, por fidelidade ou por covardia, por desejo de enriquecer a existência ou por medo da perda, por revindicação da complexidade ou por necessidade de compensação. Seus duplos pertencimentos, tanto quanto o desejo de dar conta das sutilezas que não estão presos em função das visões da vida tão categorizadas, unívocas, peremptórias, os conduzem a achar um refúgio no interstício, no intervalo, na fissura, no hiato, na fenda, na intermitência que são dobras da consciência ou redobras da escrita.

Entretanto, a tendência a entrelaçar as duas dimensões conduz também Tabucchi a procurar por pontos de contato entre os dois mundos que cindam os personagens. A escrita jorra e nasce também da percepção desses pontos de contato, que podem ser temas, situações, ou formas. Tentaremos perceber em certas recorrências tabucchianas seu jogo de junção entre dois universos.

\section{Interfaces}

A narrativa do sonho, como bem vimos, é à sua maneira um traço de união entre presente e passado, entre o consciente e inconsciente. Ele é não somente um jogo a-lógico, mas ele representa também uma superfície onde se projetam também as memórias e o imaginário: é, portanto a interface tabucchiana por excelência. Em Sogni di sogni (sonho de sonho), a narrativa do sonho se eleva ao posto de gênero, segundo uma formalização recorrente, misturando rigidez e flexibilidade.

Vemos se misturar os estereótipos representativos dos artistas evocados, e as reinterpretações pessoais dessas figuras se tornando personagens. Jamais memórias e invenção não tiveram contato assim tão abrupto, o repertório narrativo repousando sobre uma memória cultural coletiva, mas também sobre uma reescritura constantemente surpreendente de dados culturais. O que se joga lá no seio da memória coletiva, juntamente emitidas (dispensadas, retransmitida) e libertas de seus a priori, se joga individualmente nas narrativas de sonhos isolados com uma ou outra novidade. Muito do onirismo que contaminam as narrativas é uma manifestação do entre-lugar gerador do vazio, tanto como a narrativa do 


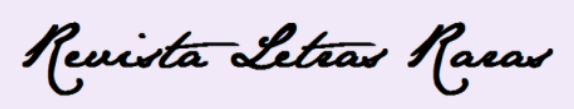

ISSN: 2317-2347 Vol. 5, Ano 5, № 1 - 2016

sonho constituído representa um ponto de contato deliberadamente mesclado entre duas dimensões que podem assim se misturar.

O papel da viagem é quase idêntico: se trata seja de crer em um traço de união entre duas esferas (a viagem que religa, que é supostamente o de aproximar dois seres, como em $T e$ Voglio, te chiammo, te veco, te sento, te sonno/te quero, te chamo, te vejo, te sinto, te sonho), seja, mais frequentemente, de colocar em jogo os espaços neutros onde a consciência pode se permitir viajar mais livremente entre as dimensões que ela mais gosta: espaços exóticos, trens, salas de espera de Noturno Indiano, O jogo do reverso, Os trens que vão a Madras, o gato de Cheshire, Afirma Pereira, têm por função criar as condições de um fluxo de consciência onde o ser pode, de cada vez, se questionar e se dispersar em um balanceamento tido fácil pela ociosidade passageira, colocar assim em contato as diferentes facetas de seu eu, o que é facilitado algumas vezes por encontros improváveis em outro contexto (L'arhant de Noturno Indiano, o copista de Réquiem, o doutor Cardoso de Afirma Pereira ${ }^{24}$ ).

Alguns lugares, muito menos neutros, são também carregados de uma avalanche interior: lugar de peregrinação como a casa do Phare de Réquiem, a igreja de Il Fiume, as ruas de Nova York em Cambio di Mano, etc., ou lugares de revelação, como os templos de Açores em Esperidi. Sogno informa di lettera (sonho em forma de carta), o quarto condenado ou o porão de Capodanno. Estes lugares funcionam como "passagens" onde se dissipam a troca de temporalidades ou de diferentes graus do real.

De outra maneira, é isso que é reproduzido também na forma de texto, particularmente no gênero epistolar. A carta tabucchiana é como um vetor para um contato entre presente e passado, realidade e desejo, expressão da falta e conspiração do vazio, terreno próprio para registrar o real como para transportar ao irreal, sobretudo na medida em que as cartas raramente têm um destinatário às quais elas alcançam. A carta é uma interface perfeita entre um ser e seu fantasma (Un biglietto in mezzo al mare/um bilhete no meio do mar), entre um retorno sobre o passado e um presente que o reinveste (Lettera da Casablanca/carta de Casablanca), entre um "eu" e sua memória; se é verdade que em nossa análise anterior, os personagens de Se está fazendo sempre tão tarde escrevem a uma lembrança, para os salvar, para os embelezar, ou mais raramente, para matá-los (Buono come sei/Bem como sei). Em

\footnotetext{
${ }^{24}$ Ver a propósito Inge Lanslots, Tabucchi's waiting rooms, in AA. VV., Antonio Tabucchi, "Sputini e ricerche", vol. 12, 1997, p. 51-60.
} 


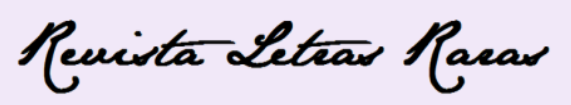

ISSN: 2317-2347 Vol. 5, Ano 5, № 1 - 2016

todo caso, a escrita mesma da carta anula brevemente o tempo, reduz a nada o frattempo (ao mesmo tempo), como afirma o personagem de Lettera da scrivere (carta para escrever) - é a sua função, sua vocação quando, apesar disso, a carta perfeita capaz de escrever de fato, ficaria sempre "a ser escrita":

Mas te digo: guarda tudo aquilo que ficou nesse meio tempo, que lembra tão impossível de perfurar como quando uma broca encontra uma pedra de granito, bem, isso não é nada, não será absolutamente um obstáculo impossível de superar quando for ler a carta que um dia lhe escrevo, uma carta na qual sempre pensei, que me acompanhou por todo esse tempo, uma carta que te devo e que te escreverei realmente, pode estar certa, te prometo. $^{25}$

A fotografia, bem como a carta, abre uma janela entre o passado e o desejo. Uma janela que tem, também, um chassis - Christine nos lembra de sua cautela no final de Noturno Indiano - o que não impede certos personagens de passar para o outro lado da imagem, como Spino em Il filo dell'orizzonte (o fio do horizonte) ou Amélia em Stanze. Interface, aqui ainda, que permite não mais ficar bloqueado no interstício das coisas, mas de passar de uma dimensão a outra a seu modo. Ao mesmo tempo, representação objetiva e suporte do imaginário, da mitologia pessoal ou familiar, a fotografia media e apaga, por seu turno, a distância dos anos. Ela é em si a representatividade do paradoxo das interfaces tabucchianas: elas apagam as fronteiras todas materializando-as: a face de contato entre dois volumes nega, por sua vez, a distinção entre estes mesmos volumes e são também suas testemunhas. Ela vai assim do sonho (no qual se revela), à carta (que não se envia), passando pelos lugares (idênticos, mas em ruínas), e também pela fotografia (que atesta, mas congela).

Outro exemplo de interface entre dois mundos que se excluem e se interpenetram é a música. Seja ela a música clássica (Para que serve uma harpa de uma corda só, Troca de Mão, Casta diva) ou a música ligeira (as canções variadas de Pequenos equívocos sem importância ou de Tristano morre, do folclore napolitano em Te veco, te chiammo... ou A che cosa serve un'arpa..., ou as canções parisienses dos anos cinquenta em Forbidden Games), a música desperta também as atmosferas do passado e é vetor do desejo. Ela provoca, tanto melhor que outra coisa, a nostalgia do vivido, tendo ao mesmo tempo o poder de criar momentaneamente a ilusão.

\footnotetext{
${ }^{25}$ Lettera da scrivere, in Si sta facendo sempre piu tardi, cit., p. 209.
} 


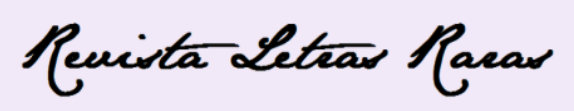

ISSN: 2317-2347 Vol. 5, Ano 5, № 1 - 2016

Que se trate, portanto, de situações (viagem, exílio), de objetos artísticos focalizando o discurso (fotografia, música), de formas textuais (carta, narrativa de sonho), vemos que a capacidade de jogar com um papel de passagem funda sua recorrência na obra tabucchiana. Seu papel de interface tem uma importância em justamedida da sensação de fissura que os personagens tentam, em vão, reduzir, enquanto não sabem desviar sua consciência dessa sensação.

É também este o sentido que é preciso dar à saturação de citações na prosa tabucchiana. Longe de ser somente uma erudição que enfeita o texto, ou uma presunção pósmoderna que teria necessidade de fragmentos do já existente para criar algo novo, a tendência à citação revela também a necessidade de estabelecer pontos de contatos entre diferentes dimensões, em particular entre presente e passado. Que Tabucchi integre ao texto de Aragon ou de Pessoa em sua escrita, ou que ele mencione o nome de um autor, que ele retorne implicitamente a filosofia de Clément Rosset, ou que ele nomeie um de seus personagens de Peter Schlemihl; que ele absorva em sua intriga os Ménines de Vélasques ou a Tentação de Santo Antônio de Bosch; que ele parodie um filme do tipo Casablanca no cinema, ou que ele faça alusão a uma canção elegante no fim de Tristano morre, essas inumeráveis aberturas para a cultura de todos os tempos e de todos os registros, do mais erudito ao mais popular, é uma maneira de criar um contato entre os dois mundos, que será gerador de uma atmosfera tanto quanto de reflexão (não ousaremos dizer de sentido).

Segundo a posição que o leitor adotará, a prosa tabuchiana se incha de múltiplas referências ou se abre para mundos passados. Essa última percepção tem o mérito de confirmar a tendência sempre em direção para a escolha dos temas, das formas, das situações, dos hibridismos, em construir o texto e a psicologia dos personagens em linhas de ruptura com o colorário de praticar sem cessar a pesquisa de pontos entre dimensões que coexistem, que se completam, e competem entre si.

Em outras palavras, escrever uma carta, resumir um sonho, pegar um trem, convocar uma fotografia, um quadro, insinuar uma música ou citar um poema são tarefas para Tabucchi relativamente homoformas: se trata, sobretudo, de pesquisar, no material literário, qualquer forma de intriga, proposta secundária, um ponto de junção entre o presente e o passado, entre o real e o irreal, entre nuance íntima e memória coletiva. É por isso que Tabucchi constrói 


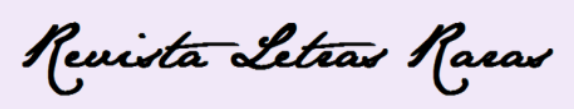

ISSN: 2317-2347 Vol. 5, Ano 5, № 1 - 2016

suas narrativas sob o princípio de interstício impossível de ser preenchido e de ser aludido, e que sua escrita não cessa de construir pontos frágeis entre dimensões rompidas, mas em universos inseparáveis.

Também reiteramos que todas as interfaces que se misturam e entram em contato umas com as outras são lugares de jogo da escrita porque são também as manifestações de um paradoxo. Essas manifestações - e, portanto, essa escrita - não seriam possíveis se nossa realidade subjetiva não fosse, por essência, intersticial e aberta: o espaço, o dia entre as coisas, é o único lugar onde percebemos nossa natureza do ser constantemente atacada pelo não-ser. É neste sentido bem particular que Tabucchi, autor do noturno, pode ser dito também autor do dia.

\title{
Perle ABBRUGIATI
}

Université de Provence - Aix Marseille I

\begin{abstract}
ABBRUGIATI, Perle. Les diaphragmes du monde. Interstices et interfaces dans l'oeuvre d'Antonio Tabucchi. Chroniques Italiennes, 2008. Disponível em < http://chroniquesitaliennes.univ-paris3.fr/PDF/web13/Abbrugiati13.pdf $>$ Acesso em 15 de maio de 2015.
\end{abstract}

Recebido em: 21/03/2016

Aceito em: 30/06/2016 